\title{
NIGROMANCIA, PRESTIDIGITACION E HIPNOTISMO EN LA CIUDAD DE MEXICO (1864-1910)
}

\section{NECROMANCY, PRESTIDIGITATION AND HYPNOTISM IN MEXICO CITY (1864-1910)}

\section{Chester Urbina Gaitán *}

\section{RESUMEN}

Los espectáculos nigrománticos, de prestidigitación e hipnotismo efectuados en la ciudad de México por artistas extranjeros, entre 1864 y 1910, fueron de acceso exclusivo de la burguesía capitalina, ya que se presentaban en los principales teatros y centros de socialización de este grupo socio-económico. Sobre la presentación de este tipo de actos se debe diferenciar los que ofrecían un espectáculo fraudulento y quienes rendían explicaciones científicas sobre sus experimentos, contribuyendo esto a que el mexicano entrara en contacto con nuevas teorías y corrientes científicas.

PALABRAS CLAVE: MEXICO * ENTRETENIMIENTO * MEDICINA * NIGROMANCIA * CLASE ALTA

\section{ABSTRACT}

The shows necromantic, prestidigitation and hypnotism made in Mexico city, by foreign artists between 1864 and 1910, were of exclusive access from the bourgeoisie capital, because they were presented in the main theaters and centers of socialization of this socioeconomic group. On the submission of such acts must differentiate fraudulent shows and who had scientific explanations about their experiments, contributing to the Mexican had contact with new theories and scientific currents.

KEYWORDS: MEXICO * ENTERTAINMENT * MEDICINE * NECROMANCY * UPPER CLASS

\footnotetext{
* Universidad Politécnica de Nicaragua (UPOLI).
} chesterurbina@yahoo.com 


\section{INTRODUCCIÓN}

La marginación socio-económica de los sectores populares en las diversiones públicas de la ciudad de México, se comienza a manifestar en el siglo XVIII, con el cobro que estipularon los comerciantes al "populacho" para ingresar a la cancha de pelota vasca que poseía la orden de San Camilo (Viqueira, 1987). Esta división social en cuanto a lo lúdico en esta urbe, se mantuvo durante todo el siglo XIX (Vázquez, 2000). A inicios del siglo xx, los menores de edad pertenecientes a los sectores pobres de la ciudad de México, frecuentaban lugares como el dancing, las peleas de box, el circo, las carpas, los toros y especialmente, el cine. Estas diversiones -en especial el cine, las carpas y los bailes- eran vistas por las autoridades como semilleros de corrupción, cultivo de enfermedades e infecciones, formadoras de delincuentes $y$ devastadoras de la moral (Sosenki, 2006: 37-38). Pese a esto, los sectores populares mexicanos no tuvieron ayuda por parte del Estado para asistir a otros espectáculos considerados más cultos como por ejemplo, el teatro (Argudín, 1985: 31).

En 1900, la ciudad de México contaba con alrededor de 400000 habitantes. La población capitalina se encontraba distribuida en forma muy irregular, concentrada en los estados del centro y en la ciudad de México. El 14\% de la población sabía leer en 1895 y un 20\% en 1910. El Distrito Federal tenía el índice de alfabetismo más alto del país; en 1895 se calculó en un 38\% y llegó al 50\% en 1910 (Pérez-Rayón, 1999: 43). En este año, la ciudad se extendía sobre una superficie de $40 \mathrm{~km}^{2}$, con una población de 471000 habitantes (Garza, 1992: 238). Entre los principales lugares de socialización $y$ descanso de la burguesía mexicana se encuentran: La Alameda, el Zócalo, el Paseo de La Reforma, Chapultepec y los Jardines de San Francisco, de Bucareli, el Tívoli de San Cosme, el del Ferrocarril y el Eliseo, el de Petit Versalles, Chateau de Fleurs, la Retama, Jamaica, Quintas del Carmen y el Jordán (Descripción de la República Mexicana 1884, 1885).

Asimismo, la ciudad contaba con otros establecimientos de esparcimiento como el circo, los teatros, las carpas, los toros, los primeros cines, una que otra sala de conciertos, el frontón, los hipódromos de Peralvillo y de Indiana, cantinas, restaurantes, cafés y para los sectores populares: las pulquerías. Para las autoridades de ese momento, quienes podían tener acceso a los lugares de entretenimiento de la burguesía eran en su mayoría hombres y algunas mujeres, las cuales tenían posesiones y conocimientos en lectura y escritura. Asimismo, este grupo se consideraba heredero de una cultura mestiza o criolla, relacionada más estrechamente con el mundo occidental que con las raíces indias; mismas que se reconocían en la antigüedad pero que se desvaloraban en el presente (Cosío, 1957: 383-398 y Pérez, 2003: 59-60).

A partir de lo anterior, el objetivo del presente artículo es determinar la importancia de los espectáculos de nigromancia, prestidigitación e hipnotismo en la sociabilidad de la ciudad de México. El periodo de estudio va de 1864 , con las presentaciones del prestidigitador de apellido Blanch, hasta 1910 con el comienzo de la Revolución Mexicana.

\section{SALUBRIDAD EN EL CONTEXTO MEXICANO}

Durante el periodo analizado, cabe decir que en el régimen del General Porfirio Díaz (1876-1911), la higiene adquirió una gran importancia para justificar obras de gran tamaño como el Gran Canal de Desagüe del Valle de México y la reconstrucción y saneamiento del puerto de Veracruz, considerando la problemática de salud a la fecha. El Consejo Superior de Salubridad, dirigido por el Dr. Eduardo Liceaga (1885 y 1914), fue apoyada por el General Díaz con la finalidad de plantear e implementar políticas para la salud pública. Asimismo, pretendió impulsar a México internacionalmente como una región dirigida hacia el desarrollo y la civilización, sin dejar de lado su identidad americana.

En esa misma línea, al Dr. Liceaga se le reconocen sus aportes en materia sanitaria, dentro de los cuales destacan: la promoción de la medicina científica para la resolución de los problemas sanitarios, la aplicación de la vacuna antirrábica y el tratamiento para la tuberculosis basado en el análisis microbiológico y el saneamiento de la ciudad de México. Pese a esto, el 
Consejo Superior de Salubridad mantuvo como su radio de acción principal al Distrito Federal (Aréchiga, 2007: 59-60).

Aún así, para mediados de diciembre de 1898, El Imparcial comunicaba que personas de cierto rango intelectual defendían las curaciones por medio de la sugestión, realizados por el brujo del callejón de Girón. Dicho periódico validaba estos actos indicando que los hechos no tenían más que una sola explicación: que en ciertas dolencias, particularmente, en las perturbaciones dinámicas del sistema nervioso, la influencia moral, ejercida por la imposición de una idea, determina su realización. Es decir, se consideraban fenómenos de "sugestión", agrupados en torno a un cuerpo de doctrina, todavía sin gran cohesión (El Imparcial, 17/12/1898). Cabe destacar que a principios del siglo $\mathrm{xx}$, es evidente la ausencia de presentaciones de compañías y artistas de los actos de nigromancia, prestidigitación e hipnotismo.

\section{ESPECTÁCULO EXCLUSIVO, APLICACIÓN MÉDICA Y PÉRDIDAS ECONÓMICAS}

Las compañías y artistas de nigromancia, prestidigitación e hipnotismo que llegaron a la ciudad de México durante 1864-1910, provenían de los Estados Unidos. Una vez terminada su actuación en la capital, tenían la posibilidad de presentarse en Puebla o en otras ciudades del país, así como, retornar a los Estados Unidos o seguir rumbo a Centroamérica y Sudamérica. Para el investigador Gerardo Lara, la conquista española le impuso a los pueblos americanos $y$ a sus religiones un lugar dentro de su cosmovisión occidental, y el nicho que se les asignó fue el de naciones inferiores presas del demonio, así lograron apropiárselas y dotarlas de un significado compatible con sus arquetipos del universo. Así, categorías como superstición y adivinación fueron atribuidas a las prácticas indígenas $y$ sus especialistas $y$ sacerdotes fueron llamados dogmatizadores o falsos profetas. Sin embargo, a medida que colonización y evangelización avanzaron, los indios incorporaron esas categorías importadas a su propio bagaje cultural y terminaron por construir nuevas parcelas culturales, en las que el común denominador fue un imaginario cristiano nativo. A ese mundo pertenecieron muchos de los designados falsos profetas indígenas coloniales (Lara, 09/07/2012). Con base en lo anterior, se puede afirmar que la presentación de actos nigrománticos no eran desconocidos en la ciudad de México; sin embargo, su presentación por parte de artistas extranjeros — principalmente europeos - fue recibida con beneplácito por la burguesía capitalina, la cual se encontraba ávida de entretenimientos.

Las presentaciones de nigromancia en la ciudad de México comenzaron en la noche del viernes 30 de diciembre de 1864, con las actuaciones que el célebre prestidigitador de apellido Blanch realizaba en el Gran Teatro Imperial (llamado posteriormente, Gran Teatro Nacional): actos de nigromancia, sicomancia, encantamientos y escamoteos. Su representante era don Enrique Font (La Sociedad, 30/12/1864: 4). A finales de noviembre de 1870, en el Teatro Iturbide se ejecutaban actos de nigromancia y magia (El Ferrocarril, 19/11/1870: 4). A principios de diciembre de 1879, Adelaida Oriliasqui se promocionaba como una profesora conocida en todo el mundo, por el acierto de sus cálculos científicos en el arte de la nigromancia. Adivinaba el pasado, el presente y el porvenir por medio de los naipes egipcios. Puso su estudio en la calle de don Juan Manuel nro. 24 entresuelo. Daba consultas personales o por correspondencia, todos los días desde las nueve de la mañana. Resaltaba que curaba de manera pronta y radical las enfermedades de las vías respiratorias, fiebres, tercianas y disenterías ( $E l$ Siglo Diez y Nueve, 09/18/1879: 4). Respecto a la llegada de estos curanderos se tiene que estas personas en su práctica vincularon lo tradicional y lo moderno, lo racional y lo irracional, lo ilícito y lo oficial, fungiendo como puentes, en el universo de las clases populares, constituyendo un peligro ideológico y comercial en la implementación del proyecto higienista de la clase dominante (Molina y Palmer, 1996: 105). A finales de noviembre de 1899, en el Teatro-Circo Orrin se presentaba la Compañía Excéntrica Italiana, la cual brindaba actos de ilusionismo y nigromancia (La Patria, 29/11/1899: 3).

Asimismo, en los inicios de la prestidigitación era conocido que J. Antonio Vargas 
(1865), un antiguo empleado en la oficina del correo, efectuaba actos de este tipo en su casa de habitación (La Sociedad, 1865a: 3). En 1868, al carecer de todo recurso, ya que no disfrutaba de la pensión que le correspondía, ofrecía sus servicios en actos de este tipo, en la calle del Hospicio de San Nicolás nro. 25 (El Monitor, 22/08/1868: 4). En la noche del viernes 8 de diciembre de 1865, en el Teatro Principal se dio una función de prestidigitación a cargo de Mr. Reynolds, la cual fue de agrado para las presentes. El martes 12 de diciembre se efectuó la misma función junto con la exhibición de un tigre africano y la difícil suerte de magnetismo sobre una niña de ocho años, conocida como la suspensión aérea (La Sociedad, 1865b: 3).

Por su parte, el Teatro de América anunciaba para el sábado 7 de noviembre de 1868, el comienzo de los actos de verso, zarzuela, baile, prestidigitación, canto y títeres ( $E l$ Constitucional, 03/11/1868: 3). En noviembre de 1870 , Mr. Morey presentaba sus actos de prestidigitación en el Teatro Iturbide (El Monitor, 22/11/1870: 3). A mediados de diciembre del citado año, el joven mexicano Antonio Arriaga ejecutó un acto de este tipo en el Teatro Nacional (La Voz de México, 13/12/1870: 2). Posteriormente, para el viernes 3 de febrero de 1871, don José M. Bonilla presentaba en este local, unas suertes cuyas entradas eran dedicadas al club central de la capital (El Siglo Diez y Nueve, 03/02/1871: 4).

Para el miércoles 19 de julio de este año, en el Casino de San Cosme, don Manuel de Echávarri practicó unas suertes de prestidigitación (El Siglo Diez y Nueve, 23/07/1871: 2). A principios de mayo de 1872 , en el Teatro Nacional se presentaba una compañía japonesa de funambulistas y de prestidigitadores ( $E l \mathrm{Mo}$ nitor Republicano, 12/05/1872: 2). A mediados de marzo de 1874, el prestidigitador argentino Julio F. Bosco, se encontraba dando funciones (El Monitor Republicano, 15/03/1874: 1), de quien se sabe que no dio un buen espectáculo (El Monitor Republicano, 07/02/1875: 2). El 18 de marzo del año antes citado, don Francisco Vargas daba una función de este tipo en el Teatro del Conservatorio (El Siglo Diez y Nueve, 18/03/1874: 3). A principios de abril de 1874 , se encontraban en la capital los prestidigitadores Fay y Keller (La Colonia Española, 02/04/1874: $3)$. En una función que estos personajes dieron el domingo 5 de abril del año en mención, el señor Fay aclaró que en la ejecución de sus actos no tenía por compañero al diablo, ni era su ánimo propagar las ideas espiritistas o inculcar doctrina alguna de este género ( $L a$ Iberia, 07/04/1874: 3). Acerca de las actuaciones de ocultistas, hipnotizadores y médium, se debe diferenciar los que ofrecían un espectáculo fraudulento de quienes rendían explicaciones científicas sobre sus experimentos, contribuyendo esto a que el mexicano entrara en contacto con nuevas teorías y corrientes científicas.

Para mediados de febrero de 1875, el Dr. Mehay ofrecía actos de prestidigitación $(E l$ Siglo Diez y Nueve, 16/02/1875: 2). El domingo 4 de marzo del año en mención, en el Gran Teatro Nacional, el conde Ernesto Patrizio desarrolló actos de taumaturgia, números de prestidigitación según las últimas innovaciones de la Escuela Americana y de la Palingenesia. Asimismo, exhibió actos de nigromancia (El Siglo Diez y Nueve, 03/03/1877: 4). En este mismo escenario se presentó en la noche del domingo 10 de agosto de 1879 , el mexicano Ricardo Vargas, quien dio números de física, magia, adivinaciones y ligerezas de manos. Lo recaudado en esta función se destinaría al pago de la deuda americana (El Siglo Diez y Nueve, 09/08/1879: 4).

En agosto de 1880, en el Salón del Tívoli del Eliseo, el profesor italiano Antón Poletti daba dos horas de prestidigitación y magia natural $(E l$ Socialista, 15/08/1880: 3). A inicios de setiembre del mismo año, se presentaba en el Teatro Principal, la señora Victoria Berland quien ejecutaba actos de prestidigitación, escamoteos y fenómenos magnéticos (El Padre Cobos, 11/09/1880: 8). A finales de enero de 1882, llegó a la capital el Circo Orrin, el cual brindaba actos de prestidigitación a cargo del payaso Ricardo Bell ( $E l$ Telégrafo, 02/04/1882: 1).

En noviembre de 1884, el señor Pedro Moreno dio varias suertes de prestidigitación en una velada familiar (Diario del Hogar, 23/11/1884: 4). El jueves 16 de julio de 1885, 
en la Plaza del Carmen se efectuaron varios números de prestidigitación, óptica, acústica y pirotecnia (Diario del Hogar, 19/07/1889: 1). Para finales de setiembre de 1887, doña María D'Escazos ejecutaba varias suertes de prestidigitación (El Siglo Diez y Nueve, 24/09/1887: 3). En agosto del siguiente año, Mr. Keller daba en el Gran Teatro Principal, varias funciones de magia negra y prestidigitación (El Monitor Republicano, 19/08/1888: 4).

Para enero de 1892, en el Teatro Invierno, el señor Balabrega y Emma Lynden ejecutaban actos de prestidigitación, magnetismo, música original, adivinación del pensamiento $y$ desaparición de personas (Diario del Hogar, 04/01/1892: 3). Una de las últimas presentaciones del período de estudio fueron las efectuadas en agosto de 1895, en el Museo de Variedades a cargo del profesor Keller y su familia (El Monitor Republicano, 25/08/1895: 2).

Sobre las exhibiciones de hipnotismo se dispone de la información la cual señala que para finales de febrero de 1887, J. D. Morales, Ferreol Labadie y J. F. Fénelon ponían a disposición de los médicos y del público en general, un consultorio de este tipo en la casa nro. 6 del Puente de San Francisco. La consulta era diaria de 5 a 6 de la tarde. Se recomendaba el hipnotismo para el alivio eficaz de muchas afecciones nerviosas rebeldes (La Patria de México, 31/03/1887: 1). La utilización del hipnotismo por parte de estos galenos evidencia su grado de modernización y la asimilación de los nuevos avances médicos. En marzo del año mencionado, "La Juventud Literaria" señalaba que en la casa de algunas personas reconocidas de la capital, se habían presentado algunos fenómenos de magnetismo y de hipnotismo muy dignos de un estudio serio y meditado; asimismo, resaltaba la existencia indudable de estos fenómenos extraños e inexplicados ( $L a$ Juventud Literaria, 1887: 5). Para el jueves 31 de marzo del mismo año, el Teatro Arbeu anunciaba la presentación de un acto de hipnotismo (La Patria de México, 1887: 4).

A inicios de 1888, se sabe que los directores de los hospitales de dementes de la ciudad de México - el de San Hipólito y el de la Canoa- eran refractarios al uso del hipno- tismo en sus pacientes, porque no conocían de cerca los resultados de este tratamiento o porque temían ensayarlo (Diario del Hogar, 27/01/1888: 3). El escritor Joaquín Gómez Vergara refiere que en setiembre de 1893, el Dr. Parra practicaba el hipnotismo en el hospital de San Pablo, quien hizo varias pruebas, en un preso acusado de robo que tenía medio cuerpo paralizado, dejándolo completamente curado en una sesión. Para lograr esto, el médico hizo que el paciente fijara su vista en un objeto brillante $y$ una vez colocado en estado de sonambulismo, lo sugestionó, imponiéndole enérgicamente su voluntad y ordenándole que anduviera. Entre los fenómenos de sugestión que el Dr. Parra produjo en el enfermo, se encuentra el de haberle aplicado un papel engomado a una pierna, y que le hiciera efecto de cáustico, levantándole ámpula durante la noche (La Patria Ilustrada, 25/09/1893: 258-259).

\section{CONCLUSIÓN}

Los espectáculos nigrománticos, de prestidigitación e hipnotismo efectuados en la ciudad de México entre 1864 y 1910, por artistas extranjeros, fueron de acceso exclusivo de la burguesía capitalina, ya que se presentaban en los principales teatros y centros de socialización de este grupo socio-económico. La utilización del hipnotismo por parte de médicos nacionales - dedicados al tratamiento de dementes, principalmente- evidencia su grado de modernización y la asimilación de los nuevos avances médicos. Aunque esta modernización a un nivel general se concentró en la ciudad capital. La ausencia de presentaciones de compañías y artistas de los actos artísticos antes citados a principios del siglo $\mathrm{xx}$, se debe a las pérdidas que experimentaban estos frente al auge de actividades culturales y deportivas. Sin embargo, debe resaltarse que algunas personas practicaban tales actividades desde antes de llegar estos artistas foráneos e incluso, algunas vivían de ello.

Este declive, incluso alcanzó otras regiones, como es el caso de Costa Rica, en dónde se vieron reflejadas (Urbina, 2002: 109-112) las pérdidas que experimentaban estas prácticas frente al auge del teatro, el cine, el fútbol y el beisbol. 
BIBLIOGRAFÍA

PERIÓDICOS ${ }^{1}$

Diario del Hogar. Año IV. Nro.59. Domingo 23 de noviembre de 1884.

Diario del Hogar. Año VII. Nro.114. Viernes 27 de enero de 1888.

Diario del Hogar. Año Iv. Nro.263. Domingo 19 de julio de 1889.

Diario del Hogar. Año XI. Nro.93. Viernes $1^{\circ}$ de enero de 1892.

El Constitucional. Año V. Nro.1138. Martes 3 de noviembre de 1868.

El Ferrocarril. Tomo III. Nro.269. Sábado 19 de noviembre de 1870 .

El Imparcial. Tomo V. Nro.821. Sábado 17 de diciembre de 1898.

El Monitor Republicano. Año XXII. Nro.114. Domingo 12 de mayo de 1872.

El Monitor Republicano. Año xxiv. Nro.64. Domingo 15 de marzo de 1874.

El Monitor Republicano. Año xxv. Nro. 33. Domingo 7 de febrero de 1875.

El Monitor Republicano. Año xxxviII. Nro.199. Domingo 19 de agosto de 1888.

El Monitor Republicano. Año XLV. Nro.204. Domingo 25 de agosto de 1895.

El Monitor. Año XVIII. Nro.5035. Sábado 22 de agosto de 1868.

El Monitor. Año xx. Nro. 5739. Martes 22 de noviembre de 1870 .

El Padre Cobos. 5a. Época. Nro.37. Sábado 11 de setiembre de 1880 .

El Siglo Diez y Nueve. Año Trigésimo. Nro.9693. Domingo 23 de julio de 1871.

El Siglo Diez y Nueve. Año xxxiv. Nro. 10953. Martes 16 de febrero de 1875.

El Siglo Diez y Nueve. Año xxxIII. Nro.10661. Miércoles 18 de marzo de 1874.

El Siglo Diez y Nueve. Año XLVI. Nro.14871. Sábado 24 de setiembre de 1887.

El Siglo Diez y Nueve. Año xxxvi. Nro.11570. Sábado 3 de marzo de 1877.

El Siglo Diez y Nueve. Año xxxviII. Nro.12329. Sábado 9 de agosto de 1879.

El Siglo Diez y Nueve. Año Trigésimo. Nro. 9523. Viernes 3 de febrero de 1871.

1 Consultados en la Hemeroteca Nacional de México
El Socialista. Año X. Nro.126. Domingo 15 de agosto de 1880.

El Telégrafo. Año 2. Nro.242. Domingo 2 de abril de 1882 .

La Colonia Española. Año I. Nro. 52. Jueves 2 de abril de 1874.

La Iberia. Año VIII. Nro. 2140. Martes 7 de abril de 1874.

La Juventud Literaria. Año I. Nro. 1. Domingo 13 de marzo de 1887.

La Patria de México. Año XI. Nro.2983. Domingo 27 de febrero de 1887.

La Patria de México. Año XI. Nro. 3010. Jueves 31 de marzo de 1887.

La Patria Ilustrada. Año XI. Nro. 39. 25 de setiembre de 1893.

La Patria. Año xxxIII. Nro.6916. Miércoles 29 de noviembre de 1899.

La Sociedad. Tomo IV. Nro. 600. Viernes 10 de febrero de 1865a.

La Sociedad. Tomo V. Nro. 902. Martes 12 de diciembre de 1865b.

La Sociedad. Tomo III. Nro.558. Viernes 30 de diciembre de 1864.

La Voz de México. Tomo I. Nro. 207. Domingo 18 de diciembre de 1870.

Siglo Diez y Nueve. Año xxxix. Nro.12426. Lunes $1^{\circ}$ de diciembre de 1879.

LIBROS

Argudín, Yolanda. Historia del teatro en México: desde los rituales prehispánicos hasta el arte dramático de nuestros días. México, DF: Panorama Editorial, 1985.

Cosío Villegas, Daniel. Historia moderna de México. México, DF: Hermes, 1957.

Garza, Gustavo (comp.). Una década de planeación urbano-regional en México, 1978-1988. 1era. reimpresión. México: El Colegio de México, 1992.

Molina Jiménez, Iván y Palmer, Steven. La voluntad radiante. Cultura impresa, magia y medicina popular en Costa Rica (1897-1932). San José, Costa Rica: Editorial Porvenir-Plumsock Mesoamerican Studies, 1996.

s.a. Descripción de la República Mexicana 1884. México, Gobierno de la República, 1885. 
Viqueira, Juan Pedro. ¿Relajados o reprimidos? Diversiones públicas y vida social en la ciudad de México durante el Siglo de las Luces. México, DF: FCE, 1987.

REVISTAS IMPRESAS

Pérez Montfort, Ricardo. "Circo, teatro y variedades. Divisiones en la ciudad de México a fines del Porfiriato. Alteridades 13 (26). México, DF: Universidad Autónoma Metropolitana-Iztapala. Juliodiciembre 2003: 27-66.

Pérez-Rayón Elizundia, Nora. "México 1900: la modernidad en el cambio de siglo. La mitificación de la ciencia”. Estudios de Historia Moderna y Contemporánea de México 18. México: unAm-Instituto de Investigaciones Históricas, 1999: 41-62.

Aréchiga Córdoba, Ernesto. "Educación, propaganda o "dictadura sanitaria". Estrategias discursivas de higiene y salubridad públicas en el México posrevolucionario, 1917-1945". Estudios de Historia Moderna y Contemporánea de México 33. Enero-junio 2007: 57-88.

Urbina Gaitán, Chester. "Circo, nigromancia y prestidigitación en San José (18671914) una aproximación desde la historia social”. Revista de Ciencias Sociales 95. San José: EucR, 2002.
Sosenski, Susana. "Diversiones malsanas: el cine y la infancia en la ciudad de México en la década de 1920". Secuencia. Revista de Historia y Ciencias Sociales 66. México, DF: Instituto de Investigaciones Dr. José María Luis Mora. Setiembrediciembre 2006.

\section{DIRECCIONES ELECTRÓNICAS}

Vázquez Mantecón, Álvaro. "La República Ludens". Estudios de Historia cultural. Difusión y pensamiento. La Rueda del Azar. Juego y jugadores en la historia de México. Ilán Semo (coord.). 2000. En: $<$ http://www.historiacultural.net/hist_ rev_vazquez.htm> [consultado el 15 de enero de 2013].

Lara Cisneros, Gerardo. "El discurso antisupersticioso y contra la adivinación indígena en Hispanoamérica colonial, siglos XVI-XviI". Nuevos Mundos. 09 de julio de 2012. En: <http://nuevomundo. revues.org/63680> [consultado el $10 \mathrm{de}$ enero de 2013].

Fecha de ingreso: 10/10/2012 Fecha de aprobación: 10/01/2013 
